\title{
Commentary: At long last-Cerebral oximetry-based goal directed therapy to prevent postoperative cognitive decline is here
}

\author{
Linda S. Aglio, MD, MS, Laverne D. Gugino, MD, PhD, and \\ K. Annette Mizuguchi, MD, PhD, MMSc, FASE
}

\footnotetext{
From the Department of Anesthesiology, Perioperative and Pain Medicine, Brigham and Women's Hospital, Harvard Medical School, Boston, Mass.

Disclosures: Authors have nothing to disclose with regard to commercial support.

Received for publication March 24, 2019; accepted for publication March 25, 2019; available ahead of print April $30,2019$.

Address for reprints: K. Annette Mizuguchi, MD, PhD, MMSc, FASE, Department of Anesthesiology, Brigham and Women's Hospital, 75 Francis St, Boston, MA 02130 (E-mail: amizuguchi@partners.org).

J Thorac Cardiovasc Surg 2020;159:954-5

$0022-5223 / \$ 36.00$

Copyright (c) 2019 Published by Elsevier Inc. on behalf of The American Association for Thoracic Surgery https://doi.org/10.1016/j.jtcvs.2019.03.066
}

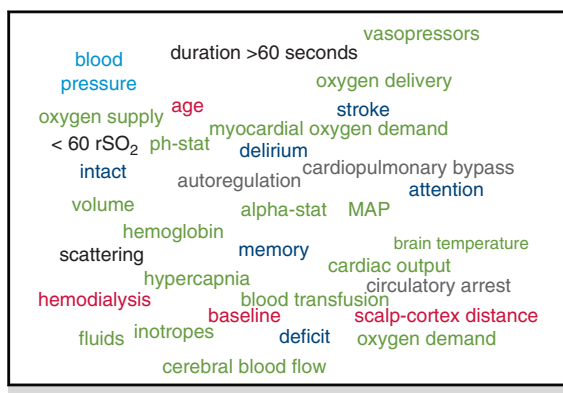

Cerebral oximetry-based goal-directed therapy may prevent postoperative cognitive deficit.

Since the Edmonds group $^{1,2}$ first reported that neuromonitoring with cerebral oximetry that was based on near-infrared spectroscopy (NIRS) provided early warning signs of oxygen delivery failure during cardiopulmonary bypass, such monitoring has become available in most centers that perform cardiac surgery. Goal-directed therapy to prevent postoperative cognitive deficits after cardiac surgery has shown utility, but most existing studies lack sufficient power to show changes or evaluated neurologic outcomes with more global end points, such as morbidity, mortality, or stroke. ${ }^{3,4}$

In this issue of the Journal, Uysal and colleagues ${ }^{5}$ report the results of a randomized, controlled trial in patients undergoing cardiac surgery with cardiopulmonary bypass. Patients in the intervention group, whose care followed a goal-directed treatment algorithm that was based on a cerebral oxygen desaturation of less than $60 \%$ for longer than 60 seconds, were compared with a control group who received standard care. Cognitive function was evaluated relative to baseline at 3 and 6 months, and response speed, processing speed, attention, and memory were tested.

Although the study of Uysal and colleagues ${ }^{5}$ was terminated early, it is important in advancing the management and prevention of cognitive impairment. This study is commendable, because Uysal and colleagues ${ }^{5}$ were able to show that the goal-directed therapy produced better outcomes in memory scores at 6 months than seen in the control group. They were unable, however, to show an association between duration or severity of desaturation and cognitive outcomes. As noted by Uysal and colleagues, ${ }^{5}$ this may be because their threshold of $60 \%$ was too mild to detect significant changes. It is also possible that they needed to focus on a more high-risk patient group, because the patients in this study seemed to be relatively healthy (mean age, 57 years; mean ejection fraction,
Central Message

Future studies that use cerebral oximetry-based goal-directed therapy in cardiac surgery may be helpful in advancing the prevention of postoperative neurologic deficits.

See Article page 943
$60 \%$ ) and did not undergo deep hypothermic circulatory arrest.

This study is also likely the first prospective, randomized controlled study to use NIRS neuromonitoring to trigger goal-directed management that showed an improvement with the intervention. The advantage of NIRS neuromonitoring is that it is a noninvasive, real-time continuous form of monitoring that can be used even during circulatory arrest. Various patient factors can influence cerebral oxygenation, however, such as brain atrophy (increase in scalp to cortex distance), low hemoglobin concentration, hemodialysis (patients undergoing hemodialysis may have lower blood flow in the frontal lobe), and low left ventricular ejection fraction (insufficient oxygen delivery). In addition, the various NIRS neuromonitoring devices cannot be compared interchangeably, even though they operate on the same measurement principles, because their algorithms for detecting and calculating cerebral ischemia are different. $^{6}$

Finally, although Uysal and colleagues, ${ }^{5}$ note as a potential limitation that their testing tool followed up on their patients remotely by allowing patients to use their home computers, the ability to follow up patients remotely may 
actually be a benefit and may be the future method of choice both for following up patients postoperatively and for screening patients preoperatively. Because one of the major pitfalls of studying cognitive impairment in patients undergoing cardiac surgery is the inclusion of patients with subclinical cognitive impairment, some type of remote preoperative testing to exclude patients with subclinical cognitive impairment may be of value.

\section{References}

1. Prabhune A, Sehic A, Spence PA, Church T, Edmonds HL Jr. Cerebral oximetry provides early warning of oxygen delivery failure during cardiopulmonary bypass. J Cardiothorac Vasc Anesth. 2002;16:204-6.
2. Edmonds HL Jr, Ganzel BL, Austin EH III. Cerebral oximetry for cardiac and vascular surgery. Semin Cardiothorac Vasc Anesth. 2004;8:147-66.

3. Murkin JM, Adams SJ, Novick RJ, Quantz M, Bainbridge D, Iglesias I, et al Monitoring brain oxygen saturation during coronary artery bypass surgery: a randomized, prospective study. Anesth Analg. 2007;104:51-8.

4. Deschamps A, Hall R, Grocott H, Mazer D, Choi PT, Turgeon AF, et al; Canadian Perioperative Anesthesia Clinical Trials Group. Cerebral oximetry monitoring to maintain normal cerebral oxygen saturation during high-risk cardiac surgery: a randomized controlled feasibility trial. Anesthesiology. 2016;124:826-36.

5. Uysal S, Lin HM, Trinh M, Park CH, Reich DL. Optimizing cerebral oxygenation in cardiac surgery: a randomized controlled trial examining neurocognitive and perioperative outcomes. J Thorac Cardiovasc Surg. 2020;159:943-53.e3.

6. Kobayashi K, Kitamura T, Kohira S, Torii S, Mishima T, Ohkubo H, et al. Cerebral oximetry for cardiac surgery: a preoperative comparison of device characteristics and pitfalls in interpretation. J Artif Organs. 2018;21:412-8. Erratum in: 2018;21: 419. 